\title{
Can a Garden Cress (Lepidium sativum: Cruciferae) Seeds be a Poisonous Bait for the Larvae of Trogoderma granarium Everts?
}

\author{
N. Al-Fuhaid* \\ Department of Biology, Sattam Bin Abdul-Aziz University, College of Science and Humanities, Kharj, Saudi Arabia \\ *Corresponding author: nfaheed@yahoo.com
}

\begin{abstract}
The Crude Extract and powder of Lepidium sativum Linn. seeds were evaluated for a toxicity effect on $5^{\text {th }}$ instar larvae of the Trogoderma granarium beetle by vapor and diet incorporation methods, respectively, as well as the repellent indicators of the powder at concentrations of $2,0.9,0.5$, and $0.1 \%(\mathrm{w} / \mathrm{w})$; the toxicity assay of essential oil was evaluated at $20,15,10$, and $5 \mu \mathrm{l} / \mathrm{L}$ air. The results show that a variety of $5^{\text {th }}$ larvae responses proved the effectiveness, where the essential oil vapors showed a high fumigate toxicity at $28.64 \mu 1 / \mathrm{L}$ air, where the LC50 was identified after 72 hours of exposure. Additionally, the powder showed a toxicity effect at the concentrations of 2, 0.9 and $0.5 \%(\mathrm{w} / \mathrm{w})$, which caused 100 and $96 \%$ mortality, respectively, and the LC50 was identified at $0.26 \%$ after 10 days of treatment. The exhibited repellent percentages of the powder were weak and at the same time had high acceptance and larval attractivity to the wheat grains treated. The attractive percentage was determined at $-53.3 \%$ and $-66.6 \%$ at the lowest and highest applied concentrations of $0.1 \%$ and $2 \%$ after 72 hours of exposure. The presence of the inverse relationship between the attractive and toxicity properties of the same material ( $L$. sativum seeds) is a promising sign to the safe modeling of toxic baits, which attract and then kill larvae.
\end{abstract}

Keywords: Lepidium sativum, weak repellent, toxic baits, attractive properties

Cite This Article: N. Al-Fuhaid, "Can a Garden Cress (Lepidium sativum: Cruciferae) Seeds be a Poisonous Bait for the Larvae of Trogoderma granarium Everts?" World Journal of Agricultural Research, vol. 6, no. 2 (2018): 31-36. doi: 10.12691/wjar-6-2-1.

\section{Introduction}

The Kingdom of Saudi Arabia is characterized by a breadth and diversity of the terrain, the weather and its agricultural features. This has resulted in diversity in the vegetation cover and thus diversity of the food culture between its regions and food culture among its nomadic, rural and urban populations [1]. It is obvious that this diversity is followed by species richness in the plantations used in drugs, folk medicine and even in cooking. This case particularly appears in most Asian countries. Some of these plants have accidentally caught the attention of farmers and the general public to control bacteria [2], viruses and insects [3]. These simple observations are considered as initial and preliminary indications that have led a large number of researchers, since the beginning of the twentieth century, to the feasibility of applying them in a deliberate manner against insects $[4,5,6,7]$. Lepidium sativum: Cruciferae is a popular medicine plant that is widespread in different regions $[1,8]$. Lepidium sativum is considered to be a multi-use plant $[9,10]$, particularly the seeds, which have been given to children to strengthen their bones and heal bone fractures [10,11].

It is also characterized as one of the medicines given for bronchitis [12,13]. Moreover, it is traditionally used as repellent against some of the insects carrying viral and bacterial diseases, such as mosquitoes [14]. Similarly,
$[15,16,17]$ reported the richness and diversity of Lepidium sativum seeds with biochemically active compounds that are well suited as antioxidants and antibacterial. All these properties encouraged the carrying out of this study to evaluate the repellency and toxicity activity of this plant on $5^{\text {th }}$ instar larvae of Trogoderma granarium: Dermestidae, which is classified as a highly stored grain pest and severely tolerant to insecticidals and fumigants $[18,19,20]$, and the adult and immature stages are destructive to more than $30 \%$ of the stored product $[21,22,23]$.

T. granarium larvae continue feeding the stored wheat grains until the endosperm of the seed, thus decreasing the quantity and quality $[20,24,25]$, and the $5^{\text {th }}$ instar larvae is the most harmful instars larvae and eater of the stored product $[23,26]$. It is known for its gluttonous eating habits and its high resistance to pesticides [27] in addition to the possession of thick hairs covering its entire body, which provide it with a kind of physical protection from impurities and pesticides mixed in with wheat grains [28], as well as its ability to withstand high temperature and humidity conditions [29].

\section{Materials and Methods}

\subsection{Insect Rearing}

In accordance with [30], to prepare homogeneous populations of the insect, the different Trogoderma 
granarium Everts stages of adults, larvae and eggs were obtained from samples of many storage products, for example, wheat grains, barley, broccoli, rice, pasta, nuts and dried fruit, which were infected by this pest. Then, these stages were bred on common wheat grains, Triticum aestivum, sterilized by freezing the wheat grains in a deep freezer at $-40^{\circ} \mathrm{C}$ for approximately three hours. Finally, the insect cultures were kept in an incubator at a temperature of $25 \pm 2{ }^{\circ} \mathrm{C}$ and relative humidity $70-60 \%$, with consideration of renewing the culture after each generation to avoid the formation a sensitive strain, and then the scientific experiments were conducted.

\subsection{Preparation of Plant Seed Powder}

Lepidium sativum Linn. belongs to the family Cruciferae, with a common name of "thefa" and "hab al rashad", and the seeds used in this study were purchased from the local market. The plant used was classified by a specialized plant classification and then cleaned of impurities and air-dried in the shade. Finally, seeds were ground in a high-voltage electric blinder, and the powder was well sifted to obtain a fine powder.

\subsection{Preparation of Crude Extract}

Accordingly [31], after drying the seeds, they were put into a device to extract the crude oil by distillation: 100 grams of dry seeds were put in water $(1: 10 \mathrm{w} / \mathrm{v})$ for three hours, and then the oil mixed with a hexane solvent was separated by a separator funnel. The oil and hexane mixture was dried by anhydrous sodium sulfate. The solvent was then disposed of using a rotary evaporator, and the oil was preserved in dark glass bottles and stored in the refrigerator at a temperature of $4{ }^{\circ} \mathrm{C}$ until used.

\subsection{Bioassay}

\subsubsection{Attractive and Repellent Activity of $L$. sativum Seed Powder}

To determine the attractive and repellent activity of the seed powder on $5^{\text {th }}$ instar larvae, we followed [32], an assay by using a wide glass dish $15 \mathrm{~cm}$ and $2.5 \mathrm{~cm}$ in diameter and height, respectively, and placed the powder in a small dish, which represents a treatment dish (TD), and a constant mix of wheat grains with determined concentrations of $0.1,0.5,0.9$, and $2 \%$ of the fine seed powder in a weight/weight ratio in the center. Every concentration was repeated six times. Additionally, a control without any treatment and ten newly molted $5^{\text {th }}$ instar larvae were evenly distributed over three replicates. Then, the wide dishes were closed by muslin cloths and rubber bands in the same culture condition. According to the [33] method, the attractive and repellent percentages were determined by counting the larvae that stayed (C) or got out of the treatment dish (TD), respectively, for the two percentages at the exposure times of 24,48 and 72 hours. The repellence percentage was calculated using the following equation:

$$
\mathrm{PR}=2(\mathrm{C}-50 \%)
$$

$\mathrm{PR}=$ percentage of repellence
$\mathrm{C}=$ percentage of $5^{\text {th }}$ instar larvae that stayed in the treatment dish (TD)

PR becomes positive if $\mathrm{C}$ is more than $50 \%$, and the treatment by plant powder has a repellent efficiency. Conversely, if $\mathrm{C}$ is less than $50 \%$, PR becomes negative, and the plant powder has an attractive effect.

\subsubsection{Diet Incorporation Toxicity}

The $0.1,0.5,0.9$, and $2 \%$ weight/weight ratios of the fine $L$. sativum seed powder were well mixed with $10 \mathrm{~g}$ of the sterile wheat grains and placed in sterile Petri dishes with a diameter of $10 \mathrm{~cm}$, and then 10 newly molted fifth instar larvae were introduced for every concentration, each repeated for six replicates. For the control treatment, the 5th instar larvae were fed non-treated wheat grains with the same conditions of the treatments mentioned above. In both the treatment and control experiments, the counts of the mortality were recorded after 4, 7, and 10 days with any changes in the behavior, morphology and activity of the $5^{\text {th }}$ instar larvae. According to [34] the formula, the correct mortality percentages were detected using the mortality in the controls at the 10th day of treatment.

\subsubsection{Fumigant Toxicity}

With some modifications, the activity of the fumigants for the crude oil of L. sativum seed powder was conducted in accordance with [35] on 10 newly molted 5th instar larvae. One microliter of the crude oil of the $L$. sativum seed powder was placed on a $20 \mathrm{~g}$ cotton ball with a diameter of $2 \mathrm{~cm}$ inside a $500 \mathrm{ml}$ glass jar for each concentration of $0.1,0.5,0.9$, and $2(\mu 1 / \mathrm{L}$ air) of the crude oil. The control cotton ball was treated with hexane only. After the cotton balls were left to dry in a fume hood, the larvae were introduced into the assay jars, and food (a few wheat grains) was placed in the treatment and control containers with six replicates for each concentration and control. After 24, 48 and 72 hours of exposure time, the mortality number was recorded in a completely randomized design by average and accumulative percentages, respectively.

\subsection{Statistical Analysis}

The mortality data were corrected with the control mortality following the formula given in Abbot. All data were statistically analyzed using a one-way analysis of variance (ANOVA, SPSS statistical analysis software, version 23). The means were compared using the least significant difference (L.S.D) at the 0.10 level.

\section{Results}

\subsection{Attractive and Repellent Activity of $L$. sativum Seed Powder}

As shown in Table 1, the results indicated the slight effectiveness of the repellent activity of the $L$. sativum seed powder toward $5^{\text {th }}$ instar larvae. For the $5^{\text {th }}$ instar larvae recorded as escaped from the food media treated by $3.67 \%$ and $3.33 \%$ at the highest concentrations of 2 and $5(\mathrm{w} / \mathrm{w})$ after 72 hours of exposure, the repellency 
percentage was zero in contrast to the attraction effect percentages $(-53.3,-46.6 \%,-53.3 \%$ and $-66.6 \%$, respectively) for the concentrations of $0.1 \%, 0.5 \%, 0.9 \%$ and $2 \%$ after 72 hours of exposure (Table 1). The results of the statistical analysis showed no significant difference in the effect of the powders used in the repellency percentage. The results showed a progressive relationship: the higher powder concentrations of $2 \%$ and $5 \%$ achieved greater attractive effect percentages compared with the untreated larvae in the control, where no abnormal results or behavioral changes were recorded. The statistical analysis showed that there were no significant effect differences on the Repellency percentage at a significant level $(\mathrm{P}<0.10)$, with significant effect of the attractive percentage

Table 1.Attractive and Repellent Activity effect of $L$. sativum seed powder on the mortality percentage of $5^{\text {th }}$ instar larvae $T$.granarium

\begin{tabular}{|c|c|c|c|c|c|}
\hline $\begin{array}{l}\text { Con. } \\
\text { w/w }\end{array}$ & $\begin{array}{c}\text { Repellency. } \% \pm \\
\text { S.E }\end{array}$ & $\begin{array}{c}\text { Attractive. } \\
\% \\
\end{array}$ & $\mathbf{F}$ & $\begin{array}{c}95 \% \text { co } \\
\text { for }\end{array}$ & $\begin{array}{l}\text { fidence } \\
\text { Iean }\end{array}$ \\
\hline 2 & $3.67 \mathbf{a b} \pm 1.856$ & -66.6 & \multirow{5}{*}{$0.062 \mathbf{a b}$} & Lower & upper \\
\hline 0.9 & $2.67 \mathbf{a b} \pm 2.186$ & -53.3 & & -4.32 & 11.65 \\
\hline 0.5 & $3.33 \mathbf{a b} \pm 2.404$ & -46.6 & & -6.74 & 12.07 \\
\hline 0.1 & $2.67 \mathbf{a b} \pm 1.453$ & \multirow[t]{2}{*}{-53.3} & & -7.01 & 13.68 \\
\hline 0.0 & $0.00 \pm 0.000$ & & & -3.58 & 8.92 \\
\hline
\end{tabular}

\subsection{Diet Incorporation Toxicity}

The toxic effect of L. sativum seed powder was tested on the mortality percentage of $5^{\text {th }}$ instar larvae. The results (Table 2) showed extermination effectiveness ranges from medium to high for all applied concentrations. The $2 \%$ and $0.1 \%$ concentrations recorded $43.3 \%$ and $10 \%$ mortality after the fourth day of the treatment, respectively, and after 10 days of treatment, it was completely a $100 \%$ and $68 \%$, respectively. Additionally, the concentrations of 0.9 and $0.5 \%$, with the progress of the treatment time, provided a steady mortality percentage from $33.3 \%$ until completely $96.4 \%$ at the fourth and tenth days, respectively.

In general, the results presented in Table 2 show an ascending relationship between the concentrations on the one hand and the time of exposure on the other hand with the mortality percentage of the $5^{\text {th }}$ instar larvae. The statistical analysis showed that there were significant effect differences on the mortality percentage at a significant level $(\mathrm{P}<0.10)$. Additionally, the LC50 of the seed powder was detected at the 10th day of exposure, and it was $0.26 \%$ closer to the concentrations of $0.1 \%$ and $0.5 \%$, which both provided $50 \%$ the mortality percentage of the $5^{\text {th }}$ instar larvae.

\subsection{Fumigant Toxicity}

Table 3 shows the toxicity results of the crude oil fumigants on the $5^{\text {th }}$ instar larvae. The significant toxicity of the $20 \mu \mathrm{l}$ concentration was recorded after 48 hours of exposure with $40 \%$ mortality; notably, the concentrations of $5 \mu \mathrm{l}$ and $10 \mu \mathrm{l}$ provided $33.3 \%$ and $27 \%$ mortality, respectively, after 72 hours of exposure. While after 72 hours, the concentrations of $15 \mu \mathrm{l}$ and $20 \mu \mathrm{l}$ were superior in killing, and the mortality percentage was increased until 100\%; moreover, the most prominent changes observed in the larvae treated with oil vapors were that they were weak and slow in movement. The statistical analysis showed that there were significant effect differences on the mortality percentage at a significant level $(\mathrm{P}<0.10)$.

Table 2. Diet Incorporation toxicity effect of $L$. sativum seed powder on the mortality percentage of 5th instar larvae $T$. granarium

\begin{tabular}{|c|c|c|c|c|c|c|c|c|}
\hline \multirow{3}{*}{$\begin{array}{l}\text { Con. } \\
\mathbf{w} / \mathbf{w}\end{array}$} & \multicolumn{3}{|c|}{ Interval/days } & \multirow{3}{*}{${ }^{*}$ Mean \pm S.E } & \multirow{3}{*}{$\mathbf{F}$} & \multirow{3}{*}{$\begin{array}{r}\mathbf{L C 5 0} \\
\mathbf{w} / \mathbf{w}\end{array}$} & \multicolumn{2}{|c|}{$95 \%$ confidence for Mean } \\
\hline & 4 & 7 & 10 & & & & & \\
\hline & $\%$ & $\%$ & $\%$ & & & & Lower & Upper \\
\hline 2 & 43.3 & 30 & 26.7 & $10.00 \mathbf{a b} \pm 1.155$ & \multirow{5}{*}{$0.482 \mathbf{a b}$} & \multirow{5}{*}{0.259} & 3.43 & 16.57 \\
\hline 0.9 & 33.3 & 30 & 33.3 & $9.67 \mathbf{a b} \pm 0.333$ & & & 8.23 & 1.10 \\
\hline 0.5 & 26.7 & 33.3 & 36.7 & $9.67 \mathbf{a b} \pm 0.882$ & & & 5.87 & 13.46 \\
\hline 0.1 & 10 & 6.7 & 46.7 & $7.00 \mathbf{a b} \pm 3.606$ & & & -8.51 & 22.51 \\
\hline 0 & 0 & 0 & 0 & $0.00 \pm 0.000$ & & & & \\
\hline
\end{tabular}

* Mean Percentage Diet Incorporation Toxicity \pm S.E row are significantly different according to the (L.S.D) at P<0.10 after 10 days. For three replicates $(\mathrm{n}=10)$. LC50 - Lethal Concentration that kills $50 \%$ of the population

Table.3. Fumigant toxicity of $L$. sativum crude extract on the mortality percentage of 5 th instar larvae $T$.granarium after

\begin{tabular}{|c|c|c|c|c|c|c|c|c|c|}
\hline \multirow{3}{*}{$\begin{array}{l}\text { Con. } \\
(\mu \mathrm{l} / \mathrm{L} \text { air })\end{array}$} & \multicolumn{3}{|c|}{ Interval/hours } & \multirow{3}{*}{$*$ Mean \pm S.E } & \multirow{3}{*}{$\mathbf{F}$} & \multirow{3}{*}{$\begin{array}{c}\text { LC50 } \\
(\mu 1 / \mathrm{L} \text { air })\end{array}$} & \multirow{3}{*}{ Slope \pm SE } & \multicolumn{2}{|c|}{ 95\%confidence for Mean } \\
\hline & 24 & 48 & 72 & & & & & \multirow{2}{*}{ Lower } & \multirow{2}{*}{ Upper } \\
\hline & $\%$ & $\%$ & $\%$ & & & & & & \\
\hline 20 & 26.7 & 40 & 100 & $10.00 \mathbf{a b} \pm 1.155$ & \multirow{5}{*}{$3.872 \mathrm{ab}$} & \multirow{5}{*}{0.259} & \multirow{5}{*}{$0.045 \pm 0.013$} & 5.03 & 14.97 \\
\hline 15 & 20 & 37 & 100 & $8.67 \mathbf{a b} \pm 1.667$ & & & & 2.93 & 14.40 \\
\hline 10 & 10 & 27 & 26.7 & $6.33 \mathbf{a b} \pm 1.333$ & & & & 0.84 & 13.50 \\
\hline 5 & 6.7 & 33.3 & 20 & $4.00 \mathbf{a b} \pm 1.155$ & & & & -0.97 & 8.97 \\
\hline 0 & 0 & 0 & 0 & $0.00 \pm 0.000$ & & & & & \\
\hline
\end{tabular}

* Means followed by the differ letters in each row are significantly different according to the (L.S.D) at $\mathrm{P}<0.10$ after 72 hours.

$*$ Mean Percentage Fumigant toxicity \pm S.E for three replicates $(\mathrm{n}=10)$. LC 50 - Lethal Concentration that kills $50 \%$ of the population. 


\section{Discussion}

The findings of the present study showed the distinguished effects of the L. sativum seed powder on the $5^{\text {th }}$ instar larvae. The more attractive activities were the larvicidal effect of the mixed powder and crude oil, and acting as a fumigant when wheat grains were provided to the treated larvae, respectively.

The double efficiency (repellency and toxicity) is described as valuable and precious because the highly $f$ attractive effect of a toxic substance to the targeted pest is a successful strategy characterized by toxic bait. Certainly, this variation of the effects is because the L. sativum seed powder possesses the chemical composition to act as an attractor to insects because its odor was accepted by the larvae.

Based on the opinion of [36], insects are always looking for a plant and its real and suitable host for food to lay eggs on, for meeting and mating, and for the small larvae that hatch. Therefore, insects accept some plants and reject others. This acceptance and rejection is significant behavior due to the differences in the chemical compounds contained in plants.

Reference [37] mentioned that some plants parts are acceptable to some insects, even if they are not their food, but only after they reach the larval body. Reference [37] also mentioned that the accepted chemical compounds at the beginning of the treatment are released, the toxic compounds that kill the treated larvae either gradually kill if the concentrations reached are low or directly kill if these concentrations are high, such as the complete mortality $(100 \%)$ that was provided by the concentrations of $2 \%$ and $20 \mu \mathrm{l}$ of the powder, and the essential oil fumigants contrasted to the $100 \%$ attractive percentage of the seed powder.

Generally, most of the increase in the toxicity or repellency activity for any treatment is expected with an increased concentration and/or exposure time [38]. According to $[39,40,41]$, the essential oils of many plants have insecticidal and repellency properties due to the mixture of compounds insecticidal in nature.

The chemical analysis of the essential oil of $L$. sativum seeds showed that the seeds contained a high proportion of compounds that have biological activity and medicinal sources $[10,42]$.

In addition, the Cruciferae family to which L. sativum belongs is one of the most distinguished plant families that contain glycoside and sulfur compounds [43], which are considered to be defensive compounds used by the plants against herbivores.

Reference [44] found that the L. sativum seeds contain the amino acid glutamic acid (19.3\%), leucine (8.21\%) and protein $(12 \%)$ that has an effect on the circulatory and digestive systems of larvae treated with powder and plant oil and confuse the function of those systems.

Reference $[14,45]$ revealed that the major components with high biological activity in the essential oil from $L$. sativum seeds were $B$-caryophyllene, eugenol, eucalyptol, sulfur, $\alpha$ - terpiny acetate and $X$-terpiny acetate.

These compounds provided the larvacidal effect against mosquito larvae, especially the eugenol [46]. Additionally, for eucalyptol [47], the bio-efficacy of eucalyptol(1,8-cineole) at LC50 was reported as 101 and $642 \mu \mathrm{g} / \mu \mathrm{l}$ against blow fly, Chrysomya megacephala (F.), and house fly, Musca domestica L., larvae, respectively.

Moreover, [48] confirmed the toxic and physiological effects of eucalyptol (1,8-cineole)(eucalyptol) on the larvae of two stored pests: the rice weevil, Sitophilus oryzae, and the red flour beetle, Tribolium castaneum.

Reference [49] reported that the 1,8-cineole (eucalyptol) has fumigant toxicity toward Callosobruchus maculatus during the first hours of treatment.

According to $[26,50]$, it is possible due to the arrival of the terpenoids and glycosides, which are the effective and main compounds of the L. sativum seed, after evaporation, that it has great ability to penetrate the outer wall of the larvae body because the compounds were lipophilic and had insecticidal activity $[49,51,52]$.

Reference [53] found out that the L. sativum seed aqueous extract killed $71 \%$ of the small stages of Bemisia tabaci nymphs. Similarly, [54] emphasized that the high pesticide effect or the activity of the crude oil fumigants of Artemisia plants on Callosobruchus maculates, Sitophilus oryzae and Tribolium castanium beetles was LC50.

Reference [55] indicated that the traditional use of $L$. sativum seed powder of applying and placing it on the skin to repel mosquitoes, domestic flies, ticks, and pest mites was effective due to its high repellency and exterminating activity.

The bio-activity and "phytotoxicity" of the L. sativum seed crude oil was evaluated [6] and was characterized by $42 \%$ biologically active compounds, as well as an effective exterminating activity, which resulted in high mortalities for Rhyzopertha dominica by testing the toxicity on contact.

The results of this study, in addition to previous studies, indicate that the powder and oil of L. sativum seeds are characterized by the high insecticidal activity on the $5^{\text {th }}$ instar larvae of the Trogoderma granarium beetle.

\section{Conclusions}

The results of this study agreed with a large number of previous studies that emphasized the importance of integrating plants, their parts and extracts, whether using oil, water or alcohol extracts, into integrated pest management. Clearly, the seeds of the L. sativum plant are indicated for their desirable signs of fighting pest larvae that represent a real economic problem in most of Asia and the Middle East. It is possible to use L. sativum powder and oil as poisonous bait in grain stores, and its use will be safer than manufactured bait. These seeds can be recommended as a good alternative to synthetic pesticides against grain pests.

One of the most important factors responsible for the insecticidal effect is the presence of chemical compounds in any form.

\section{Acknowledgements}

I would like to thank M. Al-rwais from the Prince Sattam Bin Abdul-Aziz University, the College of Science and Humanities for technical assistance, and the Department of Biology for their invaluable help in completing this study. 


\section{Statement of Competing Interests}

The authors have no competing interests.

\section{List of Abbreviations}

$\mathrm{PR}=$ percentage of repellence

$\mathrm{C}=$ percentage of $5^{\text {th }}$ instar larvae that stayed in the treatment dish

$\mathrm{TD}=$ treatment dish

\section{References}

[1] Rahman, M.A., Mossa, J.S., Al-Said, M.S. and Al-Yahya, M.A., "Medicinal plant diversity in the flora of Saudi Arabia 1: a report on seven plant families", Fitoterapia, 75 (2). 149-161. March 2004.

[2] Peterka, S. and Schlosser, E., "In vitro activity of glucosinolates against Leptosphaeria maculans in comparison to the glucosinolate content and susceptibility of seedlings of different Brassica spp. [gluconapin, sinigrin, progoitrin, glucobrassicin, nasturtiin]", Rijksuniversiteit Faculteit Landbouwwetenschappen, Gent, 54. 439-446. 1989.

[3] Negahban, M., Moharramipour, S. and Yousefelahi, M., "Efficacy of essential oil from Artemisia scoparia Waldst. \& Kit. against Tribolium castaneum (Herbst) (Coleoptera: Tenebrionidae) of the article", in Proceedings of the 4th International Iran \& Russia Conference, Agricultural and Natural Resources, Shahrekord University, 2004. 261-266.

[4] Chaubey, M.K., "Fumigant toxicity of essential oils from some common spices against pulse beetle, Callosobruchus chinensis (Coleoptera: Bruchidae)", Journal of Oleo Science, 57 (3). 171179. February 2008.

[5] Isman, M.B., "Plant essential oils for pest and disease management", Crop Protection, 19 (8-10). 603-608. September 2000.

[6] Soujanya, P. L., Sekhar, J. C., Kumar, P., Sunil, N., Prasad, C. V., and Mallavadhani, U. V. "Potentiality of Botanical Agents for the Management of Post-Harvest Insects of Maize: A Review." Journal of Food Science and Technology, 5 (53). 2169-2184. May 2016.

[7] Zia-Ul-Haq, M., Shah, M.R., Qayum, M. and Ercisli, S., "Biological screening of selected flora of Pakistan", Biological Research, 45 (4). 375-379. January 2012.

[8] Sarwar, M. and Sattar, M., "Appraisal of different plant products against Trogoderma granarium everts to protect stored wheat-a laboratory comparison", The Nucleus, 49 (1). 65-69. 2012.

[9] Ageel, A.M., Tariq, M., Mossa, J.S., Al-Yahya, M.A. and Al-Said, M.S., Plant used in Saudi folk medicine: experimental report submitted to the King Abdul Aziz City for science and technology, King Saud University Press, Riyadh, 1987.

[10] Rehman, N.U., Khan, A.U., Alkharfy, K.M. and Gilani, A.H., "Pharmacological basis for the medicinal use of Lepidium sativum in airways disorders", Evidence-Based Complementary and Alternative Medicine, 2012. 596524. October 2012.

[11] Doke, S.D. and Guha, M., "Garden cress (Lepidium sativum L.) seed-an important medicinal source: a review", Journal of Natural Product and Plant Resources, 4 (1). 69-80. January 2014.

[12] Chauhan, N.S., Sharma, V., Dixit, V.K. and Thakur, M., "A review on plants used for improvement of sexual performance and virility", BioMed Research International, 2014. 868062. August 2014.

[13] Baquar, S.R., Medicinal and poisonous plants of Pakistan, Printas, Karachi, 1989.

[14] Nadkarni, K.M., Indian materia medica, Popular Prakashan, Bombay, 1976.

[15] Kimbaris, A.C., Koliopoulos, G., Michaelakis, A. and Konstantopoulou, M.A., "Bioactivity of Dianthus caryophyllus, Lepidium sativum, Pimpinella anisum, and Illicium verum essential oils and their major components against the West Nile vector Culex pipiens", Parasitology Research, 111 (6). 2403-2410. September 2012.
[16] Radwan, H., El-Missiry, M., Al-Said, W., Ismail, A., Abdel, S.K. and Seif-El-Nasr, M., "Investigation of the glucosinolates of Lepidium sativum growing in Egypt and their biological activity", Research Journal of Medicine and Medical Sciences, 2 (2). 127132. 2007.

[17] Maier et al., A process for the preparation of dietary fibre from garden cress seeds. Indian Patent No.242/DEL, 2002.

[18] Edziri, H., Marzouk, B., Mabrouk, H., Garreb, M., Douki, W., Mahjoub, A., Verschaeve, L., Najjar, F. and Mastouri, M., "Phytochemical screening, butyrylcholinesterase inhibitory activity and anti-inflammatory effect of some Tunisian medicinal plants", South African Journal of Botany, 114. 84-88. January 2018.

[19] Hole, B.D., Bell, C.H., Mills, K.A. and Goodship, G., "The toxicity of phosphine to all developmental stages of thirteen species of stored product beetles", Journal of Stored Products Research, 12 (4). 235-244. December 1976.

[20] Golob, P. and Hodges, R.J., Study on an outbreak of Prostephanus truncatus (Horn) in Tanzania, Report G162, Tropical Development and Research Institute, London, 1982.

[21] Kerr, J.A., "Khapra beetle returns", Pest Control, 49. 24-25. 1988.

[22] Hinton, H.E., A monograph of the beetles associated with stored products, British Museum (Natural History), London, 1945.

[23] OEPP/EPPO, "Data sheets on quarantine organisms No. 121, Trogoderma granarium", Bulletin OEPP/EPPO Bulletin, 11 (1). 1981.

[24] Honey, S.F., Bajwa, B., Mazhar, M.S. and Wakil, W., "Trogoderma granarium (everts)(Coleoptera: Dermestidae), an alarming threat to rice supply chain in Pakistan", International Journal of Entomological Research, 5 (1). 23-31. June 2017.

[25] Khan, A. and Brooks, W., "A chromogenic bioluminescent bacterium associated with the entomophilic nematode Chromonema heliothidis", Journal of Invertebrate Pathology, 29 (3). 253-261. January 1977.

[26] Tripathi, A.K., Prajapati, V., Aggarwal, K.K. and Kumar, S., "Toxicity, feeding deterrence and effect of activity of 1,8-cineole from Artemisia annua on progeny production of Tribolium castaneum (Coleoptera: Tenebrionidae)", Journal of Economic Entomology, 94 (4). 979-983. August 2001.

[27] Musa, A.K. and Dike, M.C., "Life cycle, morphometrics and damage assessment of the Khapra beetle, Trogoderma granarium everts (Coleoptera: Dermestidae) on stored groundnut", Journal of Agricultural Sciences, Belgrade, 54 (2). 135-142. January 2009.

[28] Parashar, M.P., Post-harvest profile of black gram, Govt. India, Ministry of Agric. Deptt. Agric. and Coop. Directorate of Marketing and Inspection, Nagpur, 2006.

[29] Morison, G.D., "The Khapra beetle (Trogoderma granarium everts)", Proceedings of the Royal Physical Society, Edinburgh, 21 10-13. 1925.

[30] Saxena, R.C., Dixit, O.P. and Sukumaran, P., "Laboratory assessment of indigenous plant extracts for anti-juvenile hormone activity in Culex quinquefasciatus", Indian Journal Medicine Research, 95. 204-206. July 1992.

[31] Hasan, U.M., Sagheer, M., Ali, Q., Iqbal, J. and Shahbaz, M., "Growth regulatory effect of extracts of Azadirachta indica, Curcuma longa, Nigella sativa and Piper nigrum on developmental stages of Trogoderma granarium (Everts) (Coleoptera: Dermestidae)", Pakistan Entomologist, 34. 111-115. 2012.

[32] Alrubeai, H.F., Teimmi, N.K. and Al-Daragi, S.F., "Efficacy of crude extracts of Melia azedarach L. and Azadirachta indica A. Juss in killing nymphs and adults of Bemisia tabaci (Gennadius)", Arab Journal of Plant Protection, 22 (1). 47-52. 2004.

[33] Naworth, J., "Wstepne badania and atraktantami pokarmowymil replentamidla chrzas zezy wolka zbozowego (Sitophillus granarius)." Prace Nauk.IOR, 15. 179-189. 1973.

[34] Ignatowicz, S. and Wesołowska, B., "Repellency of powdered plant material of the Indian neem tree, the Labrador tea, and the sweet-flag, to some stored product pests", Polish Entomological Letter, 65 (1,2). 61-67. 1996.

[35] Abbott, W.S., "A method of computing the effectiveness of an insecticide", Journal of Economic Entomology, 18 (2). 265-267. April 1925.

[36] Ling, A.I., Sulaiman, S. and Othman, H., "Evaluation of Piper aduncum Linn. essential oil (Fam:Piperaceae) against Periplaneta americana (L.)", Iranian Journal of Arthropod-Borne Diseases, 3 (2). 1-6. December 2009. 
[37] War, A.R., Paulraj, M.G., Ahmad, T., Buhroo, A.A., Hussain, B., Ignacimuthu, S. and Sharma, H.C., "Mechanisms of plant defense against insect herbivores", Plant Signaling \& Behavior, 7 (10). 1306-1320. October 2012.

[38] Schmutterer, H. and Ascher, K.R.S., The neem tree: Azadirachta indica A. Juss. and other meliaceous plants : sources of unique natural products for integrated pest management, medicine, industry and other purposes, VCH, Weinheim, 1995.

[39] Jeyasankar, A., Chennaiyan, V. and Chinnamani, T., "Evaluation of five essential plant oils as a source of repellent and larvicidal activities against larvae of Tribolium castaneum (Herbst)(Coleoptera: Tenebrionidae)", Journal of Entomology, 13 (3). 98-103. March 2016.

[40] Park, I.K., Park, J.Y., Kim, K.H., Choi, K.S., Choi, I.H., Kim, C.S and Shin, S.C., "Nematicidal activity of plant essential oils and components from garlic (Allium sativum) and cinnamon (Cinnamomum verum) oils against the pine wood nematode (Bursaphelenchus xylophilus)", Nematology, 7 (5). 767-774. July 2005.

[41] Cetin, H. and Yanikoglu, A., "A study of the larvicidal activity of Origanum (Labiatae) species from southwest Turkey", Journal of Vector Ecology, 31 (1). 118-122. June 2006.

[42] Grdiša, M. and Gršić, K., "Botanical insecticides in plant protection", Agriculturae Conspectus Scientificus, 78 (2). 85-93. June 2013.

[43] Tandon, N. and Yadav, S.S., "Contributions of Indian Council of Medical Research (ICMR) in the area of medicinal plants/traditional medicine", Journal of Ethnopharmacology, 197. 39-45. February 2016.

[44] Burow, M., Bergner, A., Gershenzon, J. and Wittstock, U., "Glucosinolate hydrolysis in Lepidium sativum-identification of the thiocyanate-forming protein", Plant Molecular Biology, 63 (1) 49-61. December 2007.

[45] Gokavi, S.S., Malleshi, N.G. and Guo, M., "Chemical composition of garden cress (Lepidium sativum) seeds and its fractions and use of bran as a functional ingredient", Plant Foods for Human Nutrition, 59 (3). 105-111. July 2004.

[46] Chauhan, K., Sharma, S., Agarwal, N., Chauhan, S. and Chauhan, B., "A study on potential hypoglycemic and hypolipidemic effects of Lepidium Sativum (Garden Cress) in Alloxan induced diabetic rats", American Journal of PharmTech Research, 2. 522-535. 2012.

[47] Don-Pedro, K.N., "Mechanisms of action of some vegetable oils against Sitophilus zeamais (Motsch) (Coleoptera: Curculionidae) on wheat", Journal of Stored Products Research, 25 (4). 217-223. October 1989

[48] Sukontason, K.L., Boonchu, N., Sukontason, K. and Choochote, W., "Effects of eucalyptol on house fly (Diptera: Muscidae) and blow fly (Diptera: Calliphoridae)", Revista do Instituto de Medicina Tropical de São Paulo, 46 (2). 97-101. April 2004.

[49] Abdelgaleil, S.A.M., Mohamed, M.I.E., Badawy, M.E.I. and ElArami, S.A.A., "Fumigant and contact toxicities of monoterpenes to Sitophilus oryzae (L.) and Tribolium castaneum (Herbst) and their inhibitory effects on acetylcholinesterase activity", Journal of Chemical Ecology, 35 (5). 518-525. May 2009.

[50] Richards, A.G., "The chemistry of insect cuticle of the article", in Rockstein, M. (ed) Biochemistry of Insects, Academic Press, New York, U. S. A., 1978. 205-232.

[51] Lee, S., Peterson, C.J. and Coats, J.R., "Fumigation toxicity of monoterpenoids to several stored product insects", Journal of Stored Products Research, 39 (1). 77-85. January 2003.

[52] Prates, H.T., Santos, J.P., Waquil, J.M., Fabris, J.D., Oliveira, A.B and Foster, J.E., "Insecticidal activity of monoterpenes against Rhyzopertha dominica (F.) and Tribolium castaneum (Herbst)", Journal of Stored Products Research, 34 (4). 243-249. October 1998.

[53] Lamiri, A., Lhaloui, S., Benjilali, B. and Berrada, M., "Insecticidal effects of essential oils against Hessian fly, Mayetiola destructor (Say)", Field Crops Research, 71 (1). 9-15. June 2001.

[54] Ateyyat, M.A., Al-Mazra'awi, M., Abu-Rjai, T. and Shatnawi, M.A., "Aqueous extracts of some medicinal plants are as toxic as Lmidacloprid to the sweet potato whitefly, Bemisia tabaci", Journal of Insect Science, 9 (15). 1-6. May 2009.

[55] Negahban, M. and Moharramipour, S., "Fumigant toxicity of Eucalyptus intertexta, Eucalyptus sargentii and Eucalyptus camaldulensis against stored-product beetles", Journal of Applied Entomology, 131 (4). 256-261. May 2007. 